\title{
Railroad traffic light sensors to anticipate jams at junctions based on ATMega8
}

\author{
Amir Mahmud Husein ${ }^{1 *}$, Alfredy Willim ${ }^{2)}$, Yandi Tumbur Nainggolan ${ }^{3)}$, Antonius Moses \\ Simanggungsong ${ }^{4}$, Prayoga Banjarnahor ${ }^{5}$ \\ 12)(3)4)5) Universitas Prima Indonesia, Indonesia \\ 1)amirmahmud@unprimdn.ac.id, ${ }^{2)}$ alf657526@gmail.com, ${ }^{3)}$ yanditumbur43@gmail.com, \\ ${ }^{4)}$ antoniussimanggunsong20@gmail.com, ${ }^{5}$ prayogabanjarnahor07@gmail.com
}

Submitted : Aug 5, 2021 | Accepted : Oct 3, 2021 | Published : Oct 30, 2021

\begin{abstract}
Traffic congestion is a problem that has long occurred in Indonesia, especially in big cities. Traffic congestion that occurs can cause various losses, one of which is time loss because it can only run at a very low speed. Then it will create a waste of energy, because going at low speed will require more fuel. Congestion is also able to increase the saturation of other road users, not only that traffic jams also have a bad impact on nature which causes air pollution. And there are many more impacts of traffic jams that can make traveling very uncomfortable. One of the locations of traffic jams often occurs on roads located around railroad crossings. Therefore, In this study, it is proposed to make a traffic light sensor adjacent to the train track to anticipate long traffic jams based on atmega8 and infrared sensors, with the stages of collecting data, recording transportation activities at the location of the jam, then designing a sensor device. The system built is to read the volume of vehicles on the road and prioritize the road with the highest volume of vehicles to get the green traffic light condition. Based on the results of the manufacture of infrared sensors and atmega8 can be tested to reduce the level of congestion at crossroads adjacent to the railroad.
\end{abstract}

Keywords: Atmega8, Congestion, Infrared Sensors, Traffic Lights, Trains.

\section{INTRODUCTION}

Traffic lights are very important for supporting urban life in regulating the smooth flow of traffic on the highway. Traffic lights are currently being applied more by using a statistic timing system. Because of this, the existing traffic light system at the crossroads is not conductive.

Based on data obtained from the Statistics Indonesia regarding the development of the number of motorized vehicles in 2019, the number of vehicles increased by 7,108,236 units or increased to 133,617,012 units from the previous year's which was 126,508,776 units. The number of vehicles in 2018 increased by 5.9 percent, from 2017 which was $118,922,708$ units. This contributes to the volume of vehicles to exceed the capacity of the highway so that the degree of saturation becomes high and the road becomes jammed.

Traffic congestion can be disadvantageous, for example, time loss because cars can only run at a very low speed. This can waste the energy as going at a lower speed requires more fuel.

Congestion can also exhaust the road users. Traffic also gives negative impact on nature, for example; air pollution, and there are many more impacts of traffic jams that cause uncomfortable traveling.

One of the congestion points in Medan is on the railroad crossings when the train passes. This problem can cause long traffic jams during peak hours. Therefore, a solution is needed to overcome the traffic at railroad crossings..

To overcome this problem, this study applied an ATMEGA8-based sensor that can regulate traffic lights when the train is about to pass. The sensor system worked in the following process. When the train passes through the infrared sensor, the servo motor will be closed, and the ATMEGA8 starts initialization by activating the buzzer to give a warning. Then, the infrared sensor checks the number of vehicles from the traffic lights along the road. Therefore, the location with the highest volume of vehicles will get a green traffic light and the others will get a red traffic light. The goal is to minimize the road traffic around the railroad crossing. 


\section{LITERATURE REVIEW}

According to H. Himawan, the performance of fuzzy logic embedded in the microcontroller can control traffic lights with dynamic adaptive to existing vehicles on Line 1, Line 2, and Line 3. The Prototype designed traffic lights represent the environmental conditions that have multiple intersections and each intersection has four traffic lights that can communicate with agents at another intersection nearest the neighbors.

In a study conducted by M. D. Sulistiyo, the researcher implemented a fuzzy logic-based system that can be built and can learn to adopt the intelligence and intuition of traffic officers until the level of similarity to the researcher's data reaches $94.133 \%$.

In a study conducted by B. Santoso, A. I. S. Azis, and A. Bode, the researchers utilized the Fuzzy Inference System (FIS) which is often proven to show better results than static traffic light control. However, FIS. Cannot be applied to varying traffic flow or at different crossroads because this method cannot be used to see the traffic flow in real-time.

In a study conducted by Rahmawati, I \& Hariyanto, T, 2020, the traffic light control system was found to be mostly done manually. Therefore, a device with an automatic system without human interference was made and was proven to be quite effective in dividing the time delay of the green light at the traffic lights at each intersection to reduce congestion. This system can determine the time delay of traffic lights based on a priority scale that is determined from the congestion level of each road segment detected using ultrasonic sensors. To calculate the green light delay, congestion data is needed for each road section at the intersection. Therefore, all road traffic lights are connected to each other in a radio communication network that works on the $433 \mathrm{MHz}$ frequency..

In a study conducted by Irvan Saputra, et. al., 2020, the system built consists of a duration control device and congestion detection. NodeMCU and relay are used as traffic light duration regulators based on data obtained from the Google Firebase server and congestion detection through the NodeMCU device connected to ultrasonic sensors which can send sensor readings to Google Firebase server. The test was carried out by adjusting the condition of the empty and congested road on one of the roads. From the results of the tests carried out, the duration setting can run with a time tolerance of $<1$ second and congestion detection through ultrasonic sensors with a distance measurement tolerance of $2 \mathrm{~cm}$.

In a study conducted By Kartika, Linda; Virgono, Agus; Setianingsih, and Casi., 2018, the researchers use problem-solving techniques in Artificial Intelligence, namely Learning Decision, Tree Learning, Artificial Neural Networks and Genetic Algorithm. In this study (final project) the author chose Genetic Algorithms as an Artificial Intelligence that will be applied in the system. The Genetic algorithm is an optimization algorithm, the use of this algorithm will be applied in a system traffic light system. The design of a system on the performance of conventional traffic lights cannot work optimally because it gives the same duration in all traffic conditions that often starts traffic congestion.

In a study conducted by E. A. Nugroho, the researchers used the simulation of 4 crossroads as a model with the largest number of 25 vehicles with a maximum time of 60 seconds. The Fuzzy logic control system was used to control traffic indicator lights. The traffic system which was controlled by using Fuzzy logic control was proven to be very effective to describe the problem of traffic jams caused by the green light that takes too long to be on. The test results indicate that the change in the numbers of the vehicles at each intersection determines the length of time the greenlight is on at the intersection of the densest vehicles.

In a study conducted by $\mathrm{N}$. Rupawanti, the research design of automatic traffic light control based on ATMega328 microcontroller with proximity sensor aims to get a control system that can be used to reduce congestion at intersections that have a traffic light system. The method used in this study was qualitative and experimental methods. The trial of process was done by testing the infrared sensor.

\section{METHOD}

This study follows experimental research that aims to overcome traffic jams around the railroad crossings. The object of this study is the traffic light at the intersection of Pandu road. The ATMEGA8 is an open-source single-board microcontroller, designed to make electronics easy to use. In this study, the ATMEGA8 was used in creating sensors to overcome congestion at railroad crossings. The process of testing the ATMEGA8 in creating an infrared sensor is that the first infrared sensor will detect objects that pass at the railroad crossing. Then, the infrared sensor detects the intersection of Brigjen Katamso road and Letjen Suprapto where one of the intersections has a long traffic jam to get a green traffic light. This study was carried out for eight months starting in November 2020 until July 2021. For testing the proposed method, it was carried out at the Prima Indonesia University Laboratory with data source obtained from observation conducted in Medan. 
In this study, the research procedures are as follows:

Block Diagram System

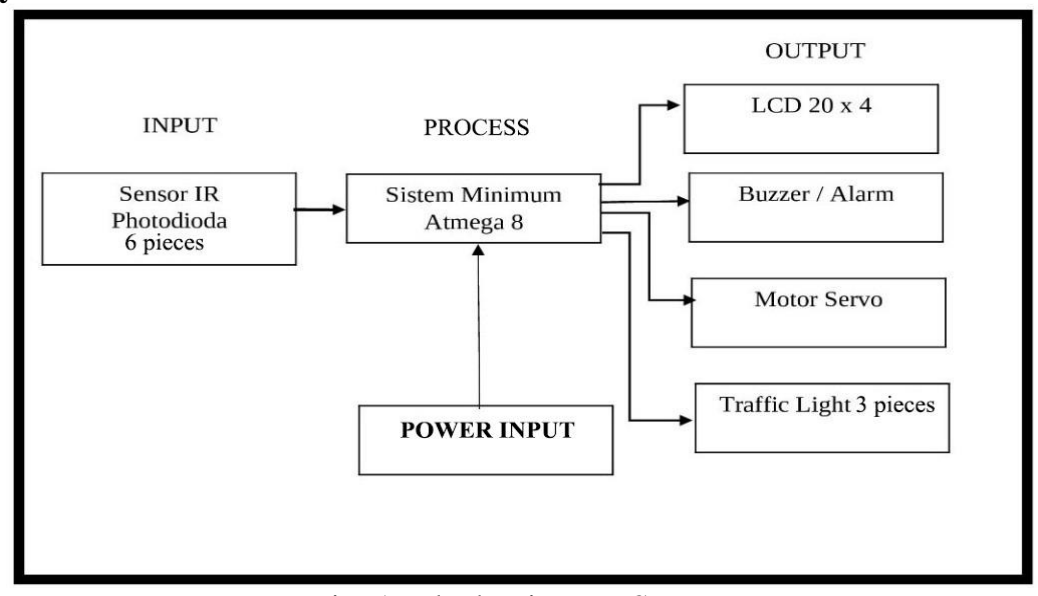

Input

Fig. 1. Block Diagram System

The Infrared Photodiode sensor is used to detect the presence of a passing vehicle or train.

Process

Is the main component that functions as a processor of data received from input, then will produce output. In this process the author uses Atmega8.

Output

Is the output of all processes that have been executed. The resulting outputs are:

a. The LCD serves as an input result indicator to display the detected conditions.

b. The buzzer functions as an indication of the input result that produces a beep sound such as an alarm or a signal warning.

c. Servo motors function as railroad cross.

d. Traffic LEDs serve as signs in traffic congestion.

\section{Research data}

The first procedure is to collect data using observation techniques. Data collection is done at 07:00 AM 09:00 AM (morning), 11:00 AM - 13:00 AM (noon), 16:30 PM - 18:30 PM (afternoon) for 2 weeks. Data collection is done manually, both at railroad crossings and traffic flows in traffic jams, such as in the morning and afternoon, or when there are no traffic jams. The data used in this study are traffic conditions found on Letjen Suprapto road, Brigjen Katamso road and Pandu road. Atmega8 will detect the traffic condition, then the tool will give an order to change the traffic light according to the number of vehicles at one intersection when the train passes. There are several examples of vehicle conditions on the Letjen Suprapto road, Brigjen Katamso road and Pandu road as follows:

\section{Letjen Suprapto Street}

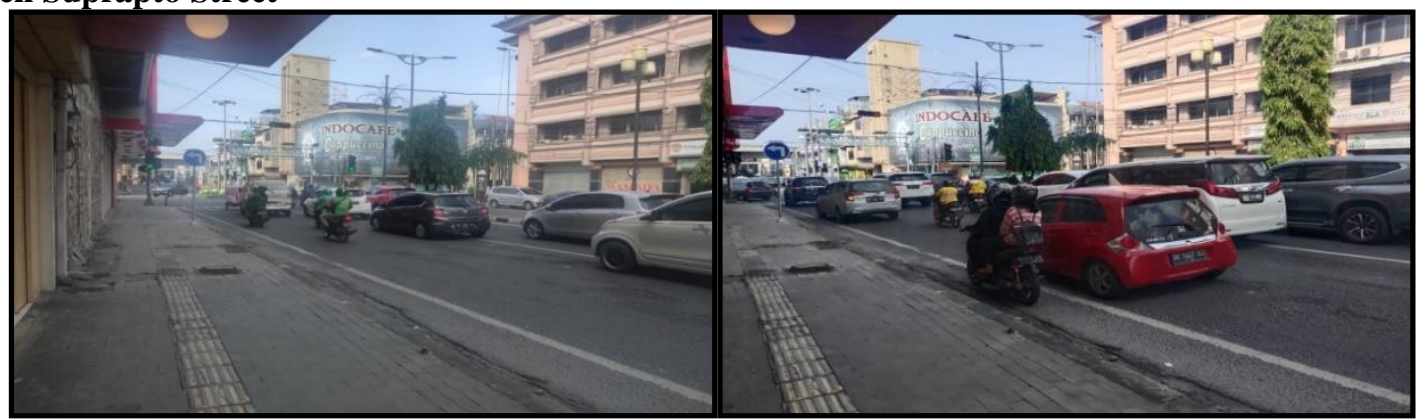

*name of corresponding author 


\section{Brigadier General Katamso Street}

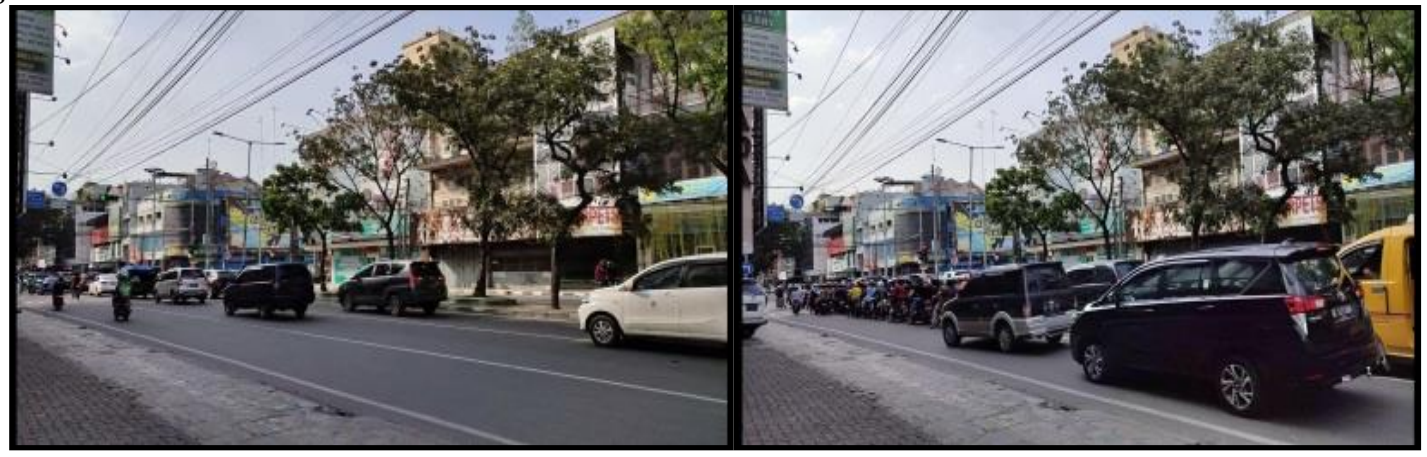

\section{Pandu Street}

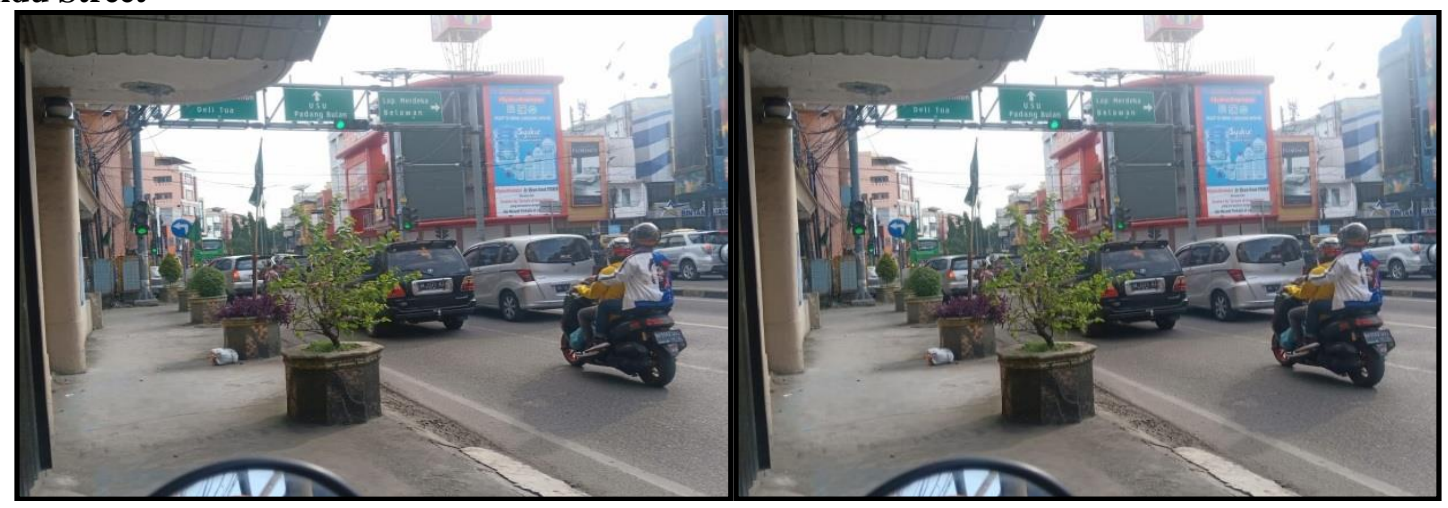

Pandu Street (Railway Location)

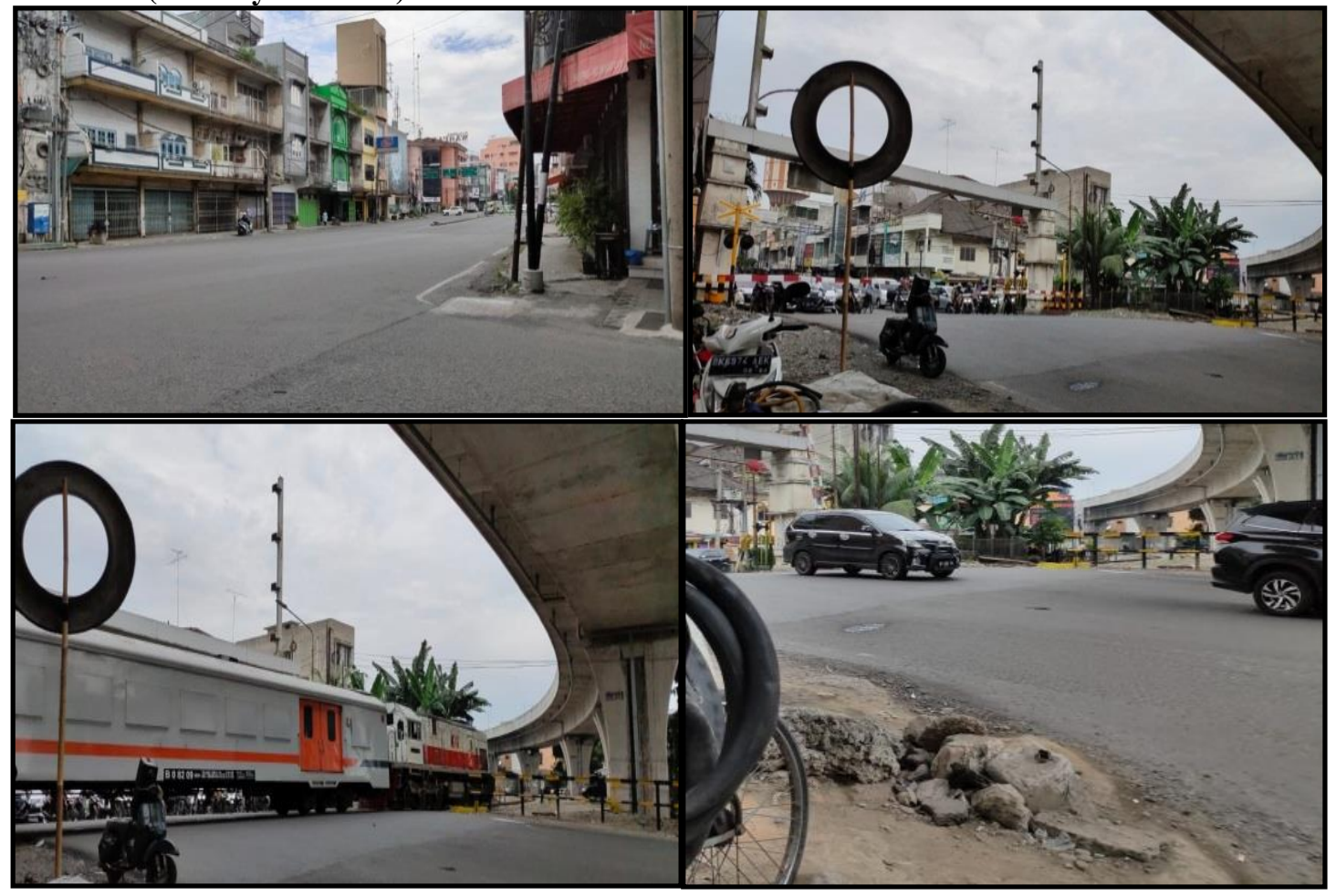

*name of corresponding author 


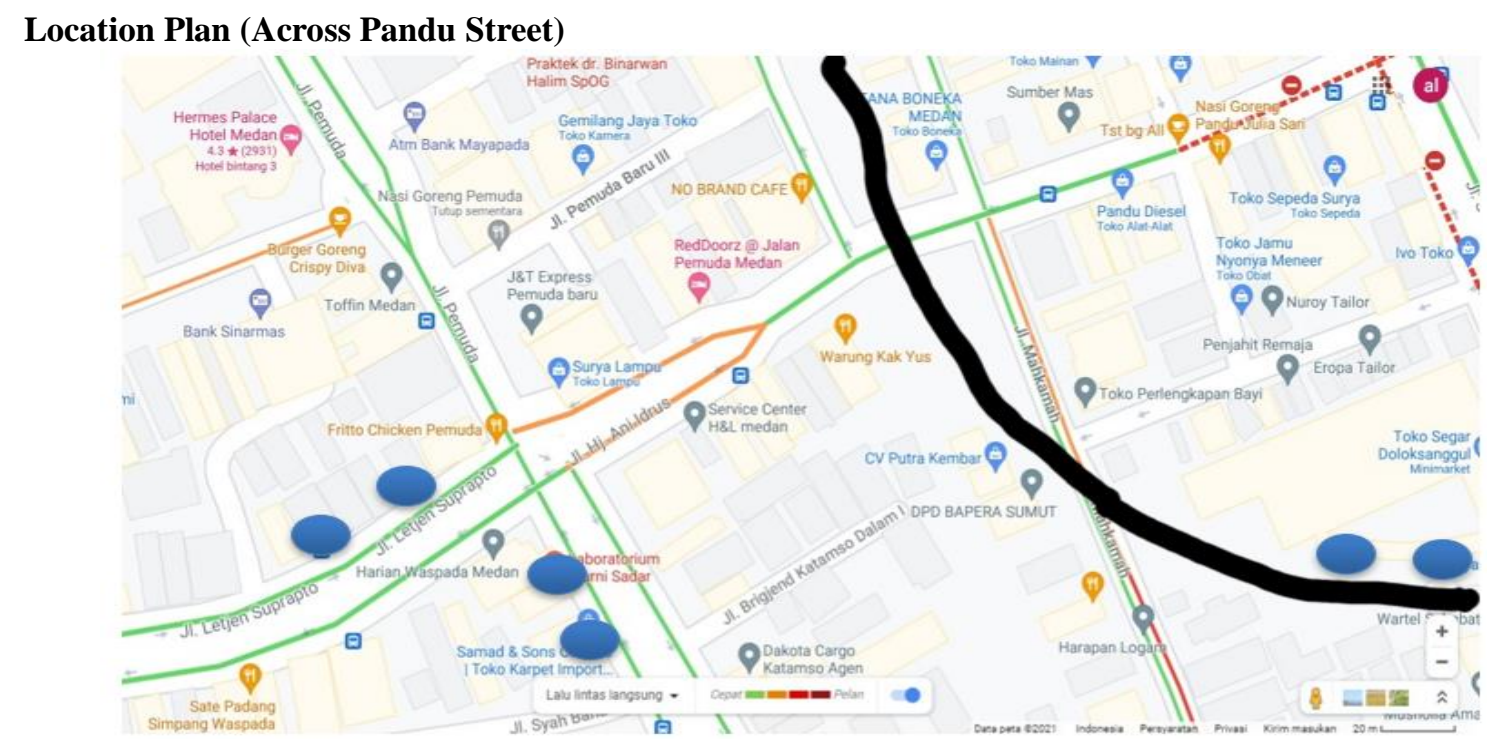

Information :

Infrared Photodiode Sensor

Railroad Tracks

\section{The Observation Data}

Based on observations conducted by the researchers for two weeks, the researchers calculated the time during which the train crossed the path of the intersection of Pandu street. The distance between the railroad tracks and the railroad cross was approximately 30 meters. Then the researchers began to calculate the number of trains passing and the time during which the train passed. On June 5, 2021, the researchers calculated the number of oil trains passing by as many as 14 carriages with a distance of 170 seconds and 10 passenger trains with a distance of 110 seconds. When the train passed, the infrared sensor will detect traffic jams on Letjen Suprapto and Brigjen Katamso Street. If long traffic jams occur on Letjen Suprapto, the traffic light will be green and if long traffic jams occur on Brigjen Katamso, the traffic light will be green with the accuracy of time during the train passing.

Table 1

The Observation Data

\begin{tabular}{|c|c|c|c|c|}
\hline \multirow{2}{*}{ Date } & \multicolumn{2}{|c|}{ The Numbers Of Railway Trains } & \multicolumn{2}{c|}{ Second } \\
\cline { 2 - 5 } & Oil Trains & Passenger Trains & Oil Trains & Passenger Trains \\
\hline $05 / 06 / 2021$ & 14 & 10 & 170 & 110 \\
\hline $06 / 06 / 2021$ & & 8 & - & 88 \\
\hline $07 / 06 / 2021$ & 10 & 11 & 121 & 121 \\
\hline $08 / 06 / 2021$ & 15 & 12 & 182 & 132 \\
\hline $09 / 06 / 2021$ & & 10 & - & 110 \\
\hline $10 / 06 / 2021$ & & 10 & - & 110 \\
\hline $11 / 06 / 2021$ & 14 & 13 & 170 & 110 \\
\hline $12 / 06 / 2021$ & & 10 & - & 121 \\
\hline $13 / 06 / 2021$ & & 11 & - & 154 \\
\hline $14 / 06 / 2021$ & 14 & 14 & 170 & 110 \\
\hline $15 / 06 / 2021$ & 12 & 10 & 146 & 88 \\
\hline $16 / 06 / 2021$ & & 8 & - & 88 \\
\hline $17 / 06 / 2021$ & 15 & 8 & 182 & 110 \\
\hline $18 / 06 / 2021$ & & 10 & - & 154 \\
\hline $19 / 06 / 2021$ & 12 & 14 & 146 & 132 \\
\hline $20 / 06 / 2021$ & & 12 & - & \\
\hline
\end{tabular}

\footnotetext{
*name of corresponding author
} 


\section{Dataset}

A dataset is a collection of data in a table that describes the relationship between the data in the table (data relations), or simply in one dataset can be seen many related table data. These datasets are objects that represent data and their relationship in memory. In this study, the device will start to work when the train passed the sensor, and a train warning sound is heard. Furthermore, the device will calculate the condition of the traffic lights around the traffic light intersection. An example of dataset on the condition of the volume of vehicles on the road around the railroad crossing area can be seen in table 1.

\section{Table 1}

Sample Dataset

\begin{tabular}{|c|c|c|c|c|c|}
\hline \multirow[b]{2}{*}{ No. } & \multicolumn{3}{|c|}{ The Number of Vehicles Volume } & \multirow[b]{2}{*}{ Red Light } & \multirow[b]{2}{*}{ Green Light } \\
\hline & Pandu Road & $\begin{array}{l}\text { Brigjen } \\
\text { Katamso Road }\end{array}$ & $\begin{array}{l}\text { Letjen Suprapto } \\
\text { Road }\end{array}$ & & \\
\hline 1. & 0 & 30 & 40 & $\begin{array}{l}\text { Pandu Rd \& } \\
\text { Brigjen } \\
\text { Katamso Rd }\end{array}$ & $\begin{array}{l}\text { Letjen } \\
\text { Suprapto Rd }\end{array}$ \\
\hline 2. & 0 & 40 & 35 & $\begin{array}{l}\text { Pandu Rd \& } \\
\text { Letjen } \\
\text { Suprapto Rd }\end{array}$ & $\begin{array}{l}\text { Brigjen } \\
\text { Katamso Rd }\end{array}$ \\
\hline
\end{tabular}

\section{Flowchart}

In designing a device, several things need to be considered, namely; how to design a device that will be designed according to the theoretical basis. Before designing a system or circuit, the flowchart needs to be created first. Flowcharts are one of the simplest ways to run the workings of a system and to make it easier to locate errors of a system. By using the flowchart we can analyze how the circuit works and we can design the hardware that will be designed in general.
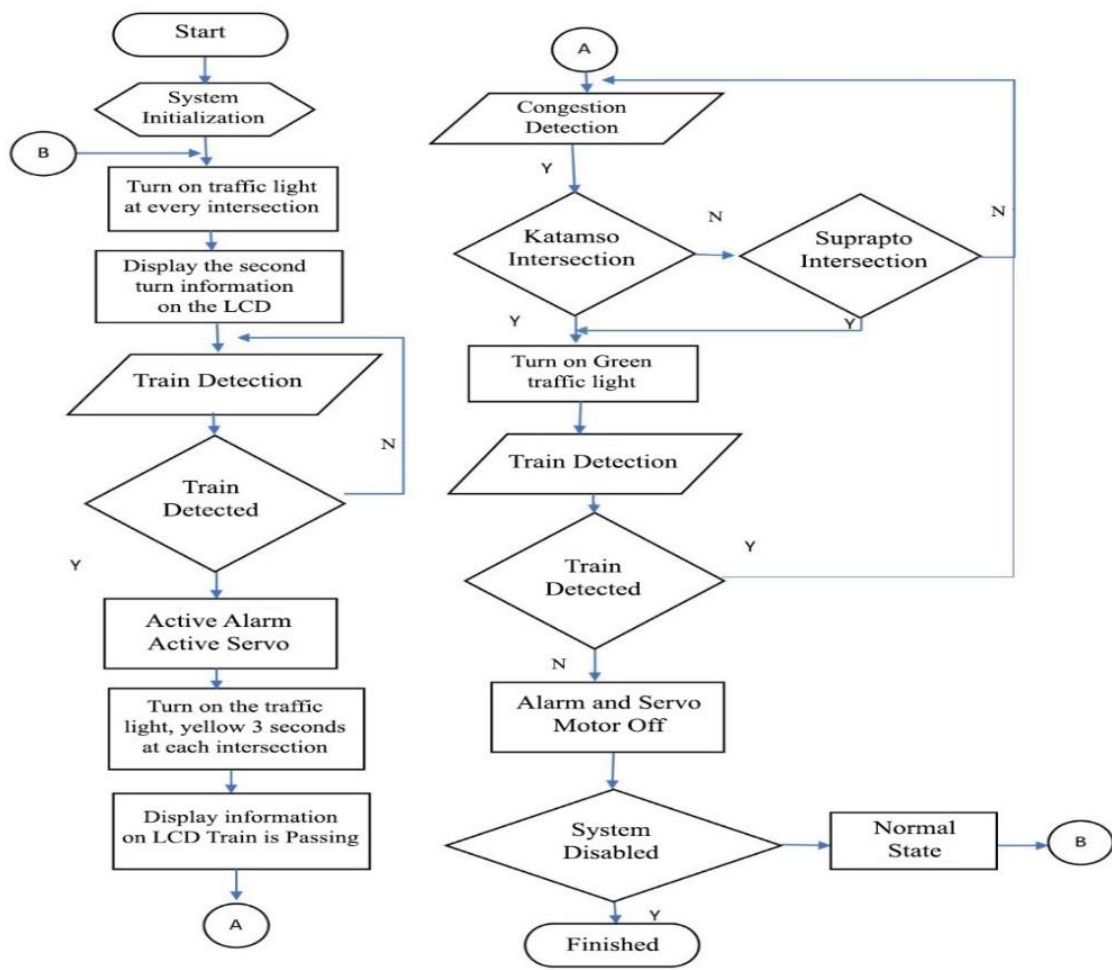

Fig. 2. Flowchart

*name of corresponding author 


\section{RESULT}

In the series of designing this device using ATMEGA8, Buzzer was used to signal that the train will pass. This equipment is made with $5 \mathrm{~V}$ adapter power source, servomotor, 20x4 LCD, Photodiode Infrared Sensor, Relay.

\section{The Process of System Activation}

In this system, the activation starts from connecting the circuit with a 5volt 2 Ampere adapter power source, the process is to install the adapter jack to the minimum system as shown below.

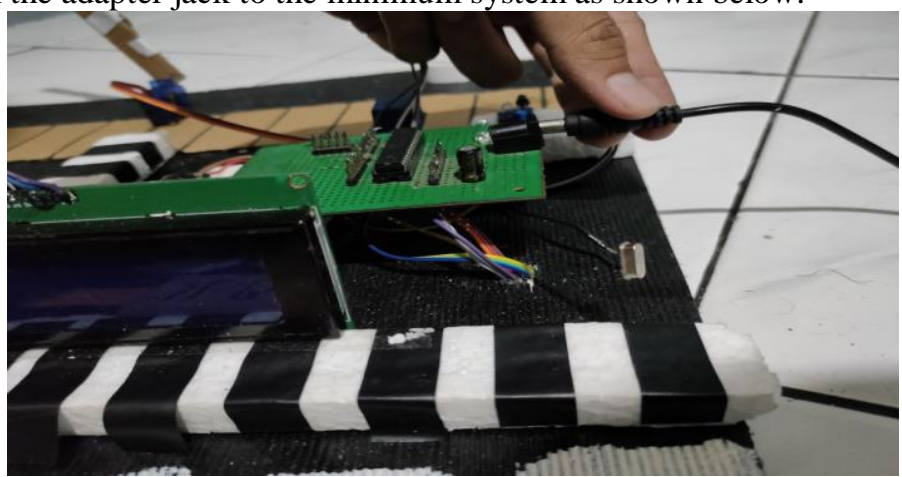

Fig. 3. The Process of System Activation

\section{The Initial State Process Of the System}

This process is the initial state after the system is connected to a power source. In this system, the LCD will display the Pandu Street, Brigjen Katamso Street, and Letjen Suprapto street. The traffic lights at this time are still in normal condition following the traffic lights, and the lights will automatically adjust the color once the sensor reads the arrival of the train and detects which road is the most congested.

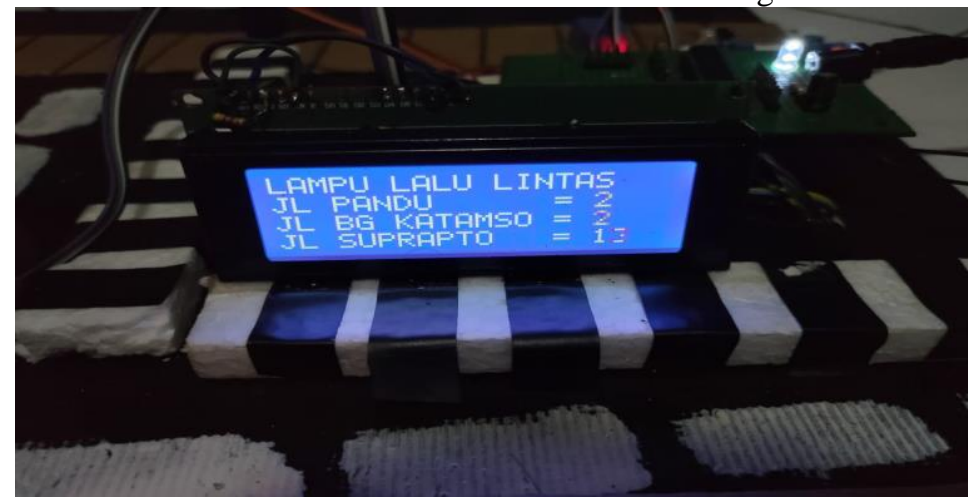

Fig. 4. The Initial State Process Of the System

The Process of Implementing the Infrared Photodiode Sensor in Detecting Trains

This process is a condition where the infrared Photodiode Sensor detects the arrival of the train, and sends the information to the ATMEGA8, and the system starts working.

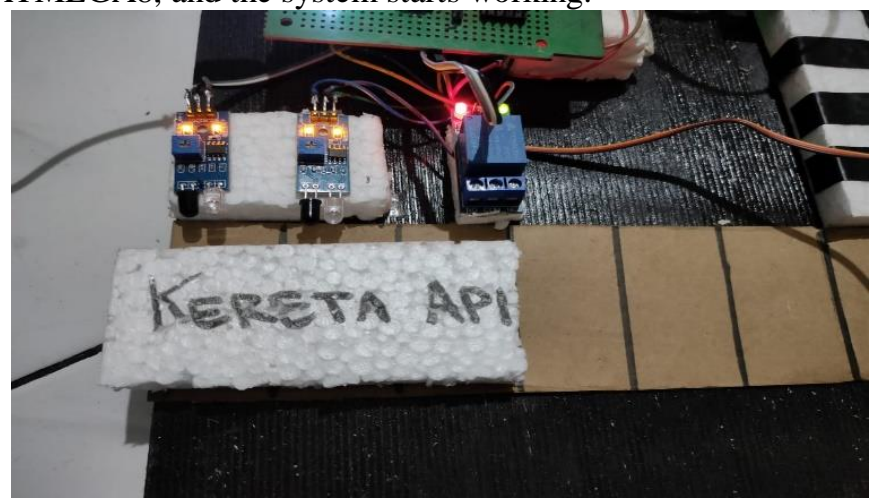

Fig. 5. IR_Photodioda Sensor in Detecting Trains.

*name of corresponding author 
The Process of Implementing a Servomotor Served as a Railroad Cross

This process is when the servomotor as a railroad cross to stop the vehicles when the train passed. The servomotor reads a message received from the ATMEGA8.

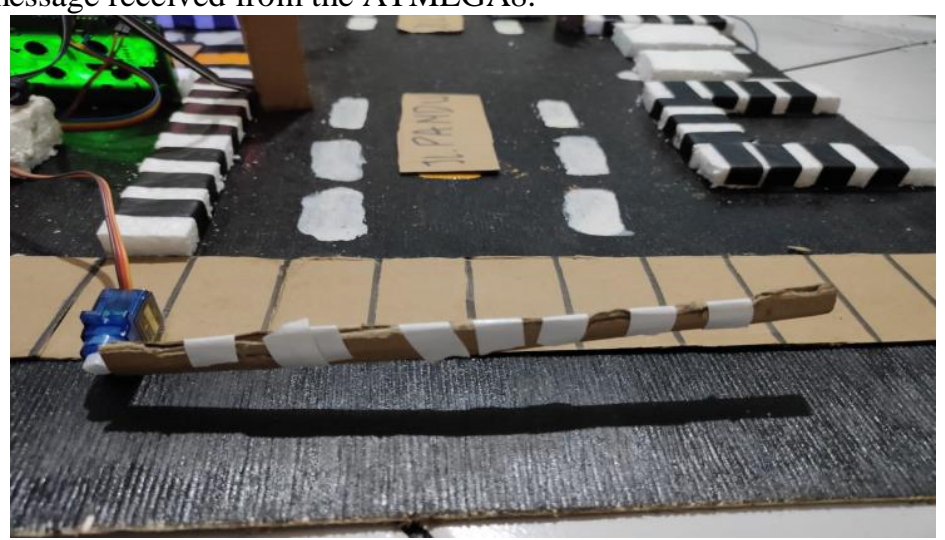

Fig. 6. Servo Motor Process As Railroad Cross.

The Process of Implementing Infrared Photodiode Sensors in Detecting Congestion on Brigdjen Katamso Street

This process is a condition of the Infrared Photodiode Sensor Detecting Traffic Congestion on the Brigadier General Katamso road when the train passes then sending information to the ATmega8 and then the system starts working.

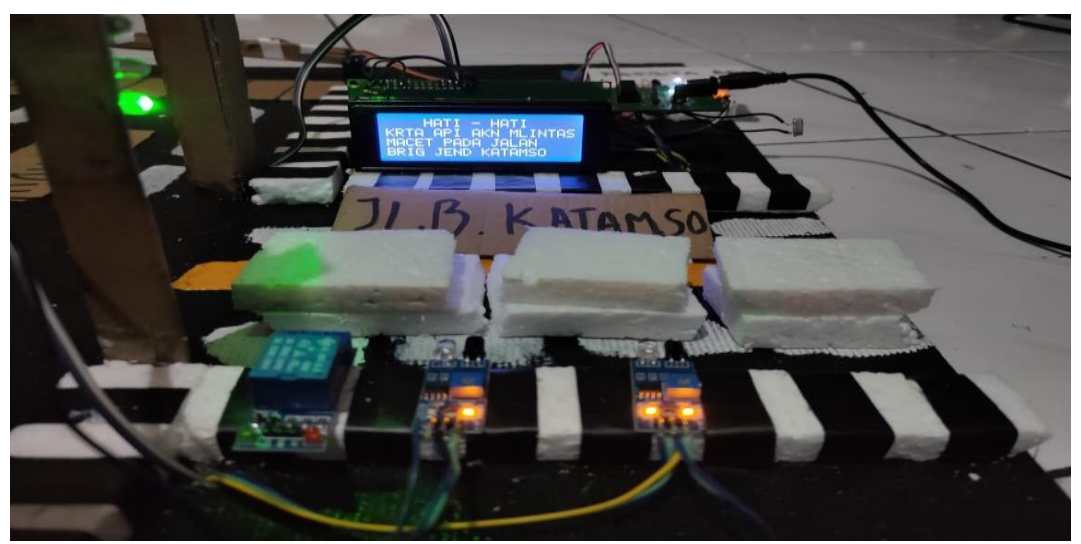

Fig. 7. IR_Photodioda Sensor State Process Detects Congestion Long On Jalan Brigadier General Katamso

The Process of Implementing the Infrared Photodiode Sensors in Detecting Congestion on Letjen Suprapto Street

This process is a condition of the Infrared Photodiode Sensor Detecting Traffic Congestion on Letjen Suprapto, and sends the information to ATMEGA8, and then system starts working.

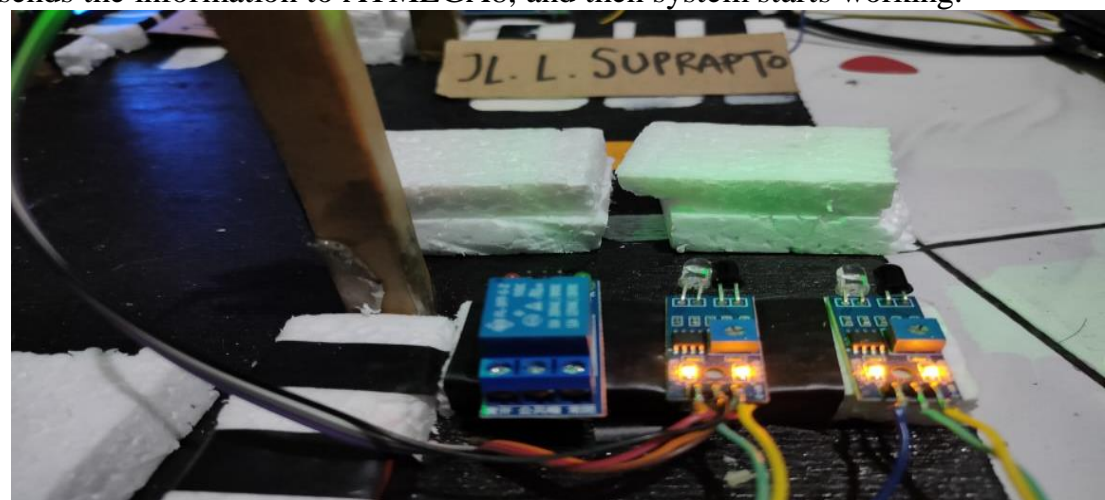

Fig. 8. The State Process of IR_Photodioda Detecting Long Traffic Jams on Letjen Suprapto Street

*name of corresponding author 


\section{The Process of Traffic Lights Turning On in Every Road}

In this process, the traffic lights are set in the program so that they can turn on in turns at each intersection. Meanwhile, when the green light turns on at Brigjen Katamso, the red light turns on in Letjen Suprapto. When the green light turns on at Letjen Suprapto, the red light on Brigjen Katamso turns red. Then, when the train crosses at Pandu Street, the street light keeps turning red. Therefore, the vehicles on the roads stop, and the traffic congestion does not occur on Pandu Street.

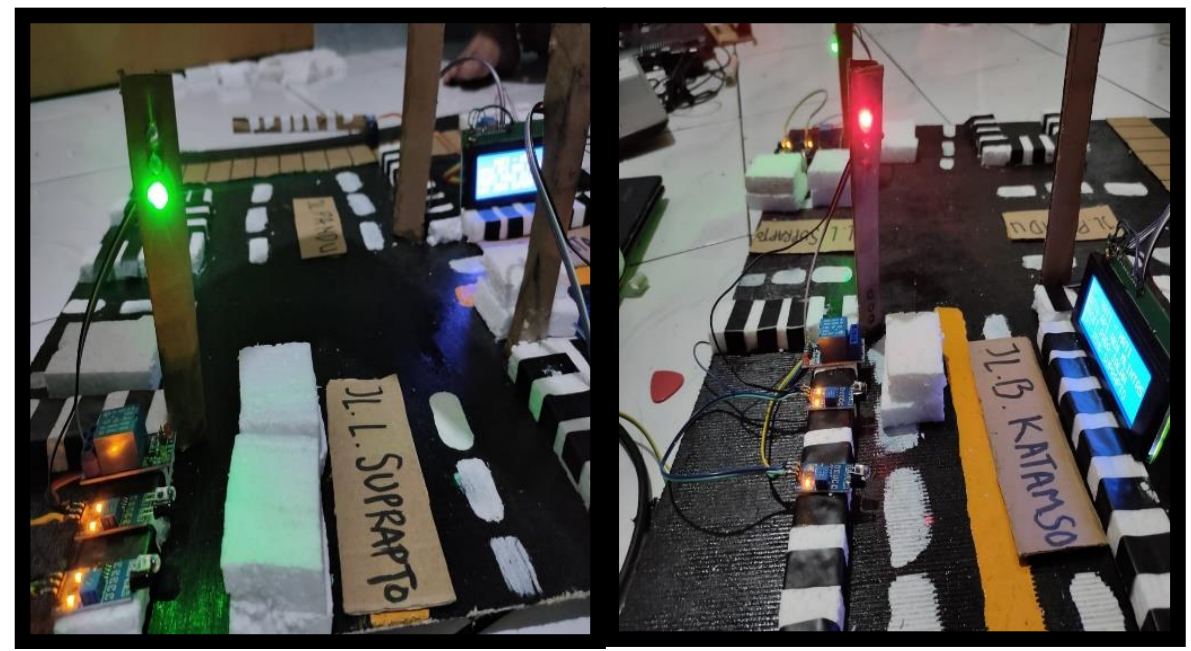

Fig. 9. The Process of Traffic Lights Turning on when traffic occurs on Brigjen Katamso.

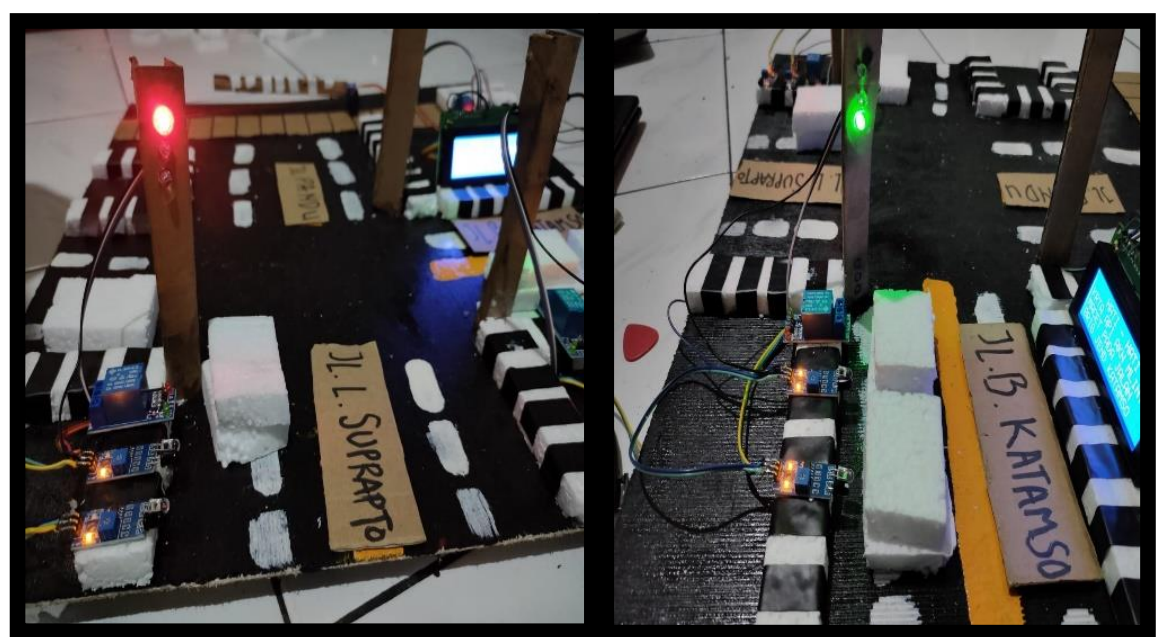

Fig. 10. The Process of Traffic Lights Turning On when the traffic congestion occurs in Brigjen Katamso

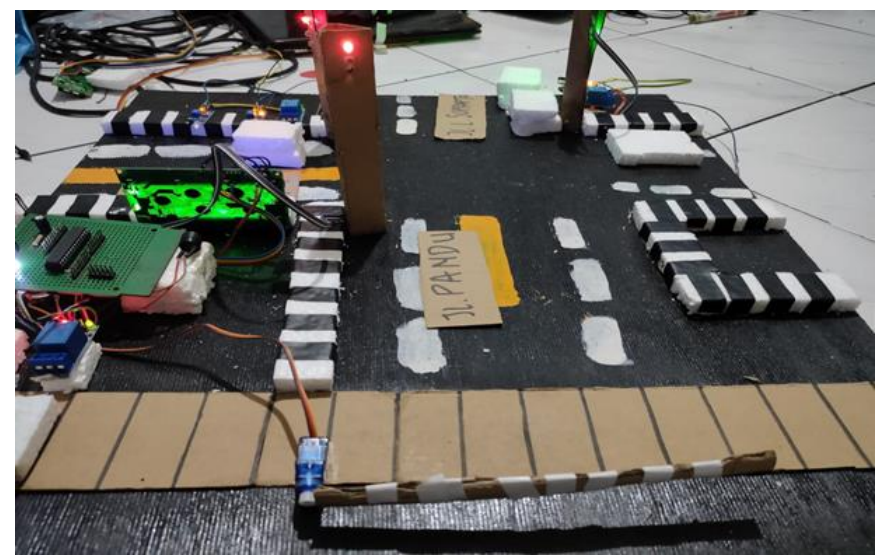

Fig. 11. The Process of Traffic Lights Turning Red in Pandu Street

*name of corresponding author 


\section{The Process Display of LCD}

In this process, the LCD will display messages and the seconds of traffic lights that take turns and vary under normal conditions. To display the seconds on the LCD, the program list at the red traffic light is given a delay of 22,000 ms with an external clock of $16 \mathrm{Mhz}$ which is 22 seconds. The yellow light is given a $4000 \mathrm{~ms}$ delay with an external clock of $16 \mathrm{Mhz}$, which is 2 seconds after the red light is on and 2 seconds after the green light is on. The green light is given a delay of $10,000 \mathrm{~ms}$ with an external clock of $16 \mathrm{Mhz}$, which is 10 seconds. In this process, the LCD will display messages and seconds of the traffic lights that take turns and vary depending on the condition of the train passing the roads.

In more detail, this can be seen in the following figure:

A. When the train is about to pass and when there is no traffic jam detected on Brigadier Katamso and Letjen Suprapto, the device displays "BEWARE THE TRAIN WILL CROSS! ROAD CONDITIONS NORMAL".

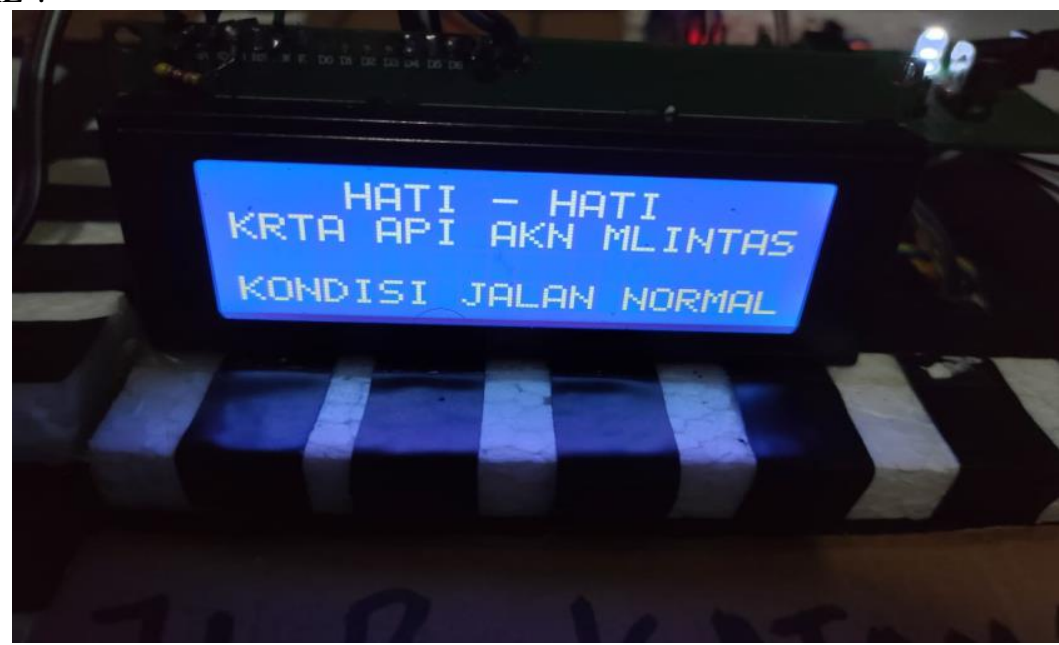

Fig. 12. LCD Display Process When the Train Will Cross

B. When the device detects a traffic jam on Brigjen Katamso, the device displays "BEWARE! THE TRAIN WILL CROSS, TRAFFIC JAM ON BRIGJEND KATAMSO AND LETJEND SUPRAPTO"

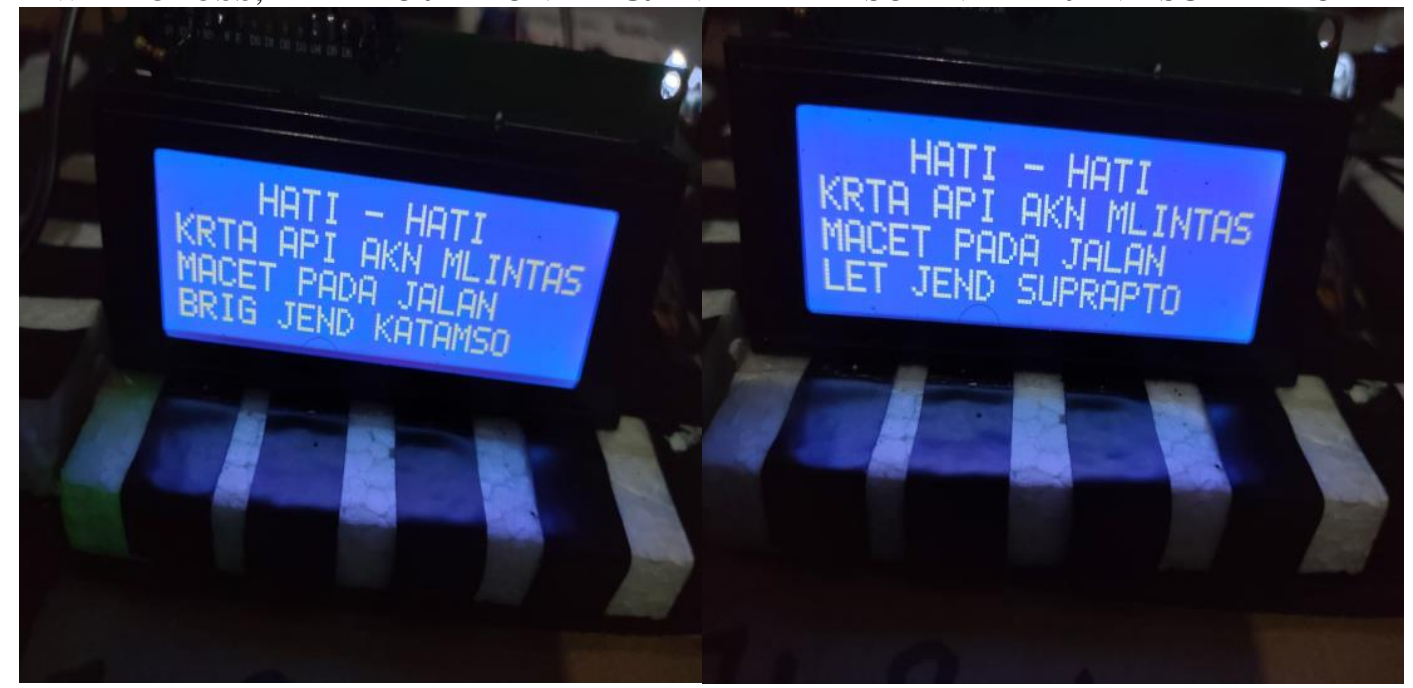

Fig. 13. LCD Display Process when the traffic congestion occurs at Brigjen Katamso and Letjen Suprapto 
C. When the traffic congestion is not detected on Brigjen Katamso and Letjen Suprapto roads, the device displays "NORMAL ROAD CONDITION".

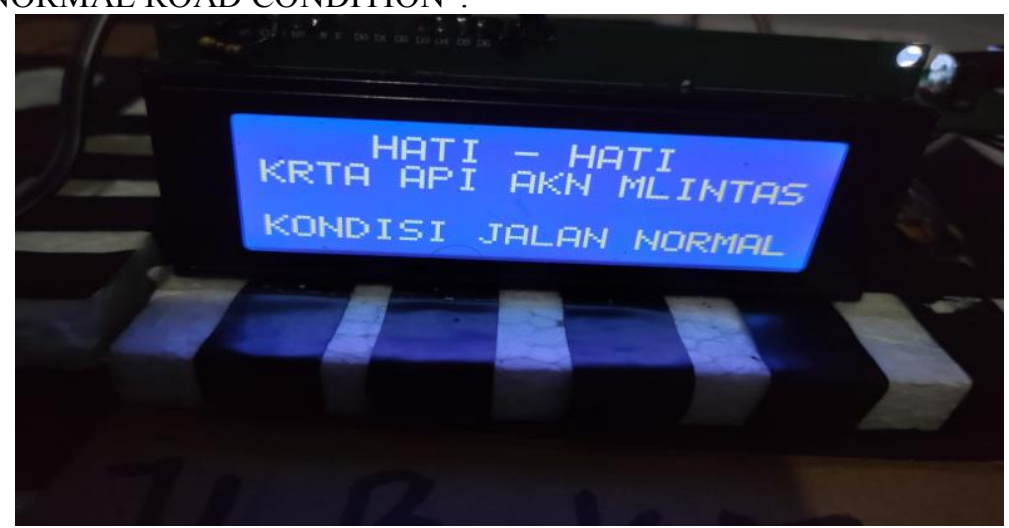

Fig. 14. LCD Display Process When no congestion Is Detected

\section{The process of Identifying the Infrared Sensor}

The identification process of infrared sensor is a step taken to obtain input which will then be processed into output. In the system, every train that is about to pass will be detected by an infrared sensor. When the infrared sensor detects a passing train, the buzzer and servomotor will function, and the traffic light will adjust the color of the lights on the road that is detected as the most jammed. Then, when the sensor does not detect a train that will pass, the buzzer and servomotor will not turn on and the traffic light conditions are normal.

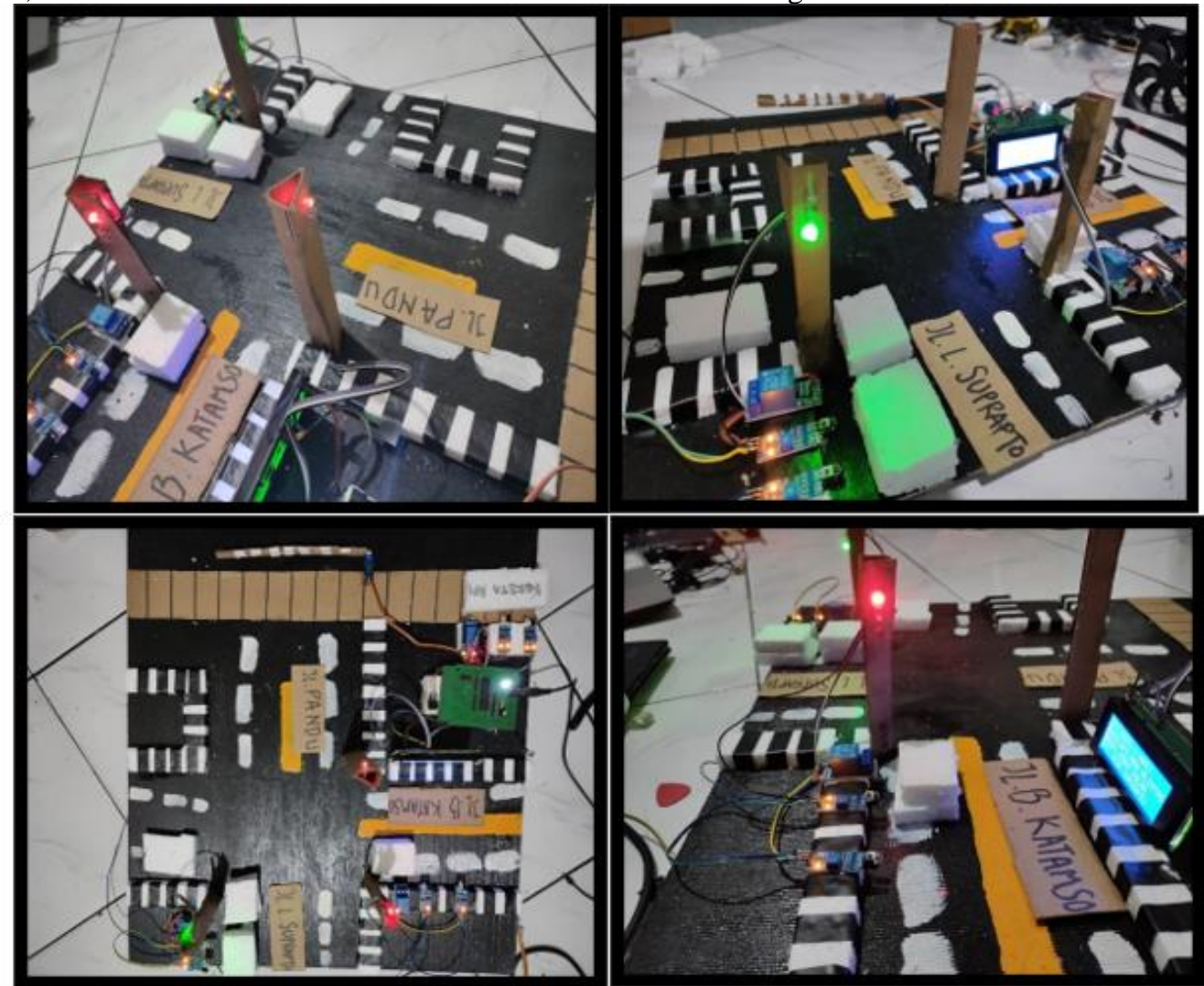

Fig. 15. Identifying Infrared Sensor when Train is detected.

The figure above shows the process of reading infrared sensor when a train is detected. It can be seen that when the train is passing, the traffic lights will automatically adjust the color of the lights to the most congested condition.

*name of corresponding author

\section{DISCUSSIONS}


Based on the results of the tests carried out on this miniature device, it was found that the device can detect traffic congestion at the intersection of Brigjen Katamso and Letjen Suprapto at the railroad crossing. Traffic congestion can be disadvantageous, for example, time loss because cars can only run at a very low speed. This can waste the energy as going at a lower speed requires more fuel.

Traffic congestion can also exhaust the road users. It can also give negative impact on the nature, for example, air pollution. There are many other negative impacts of traffic congestion that cause uncomfortable travelling.

One of the traffic congestion points in Medan can be seen around the railroad crossings that occur when the train passes. This problem can cause long traffic jams during peak hours. Therefore, a solution is needed to overcome the traffic congestion on the roads around the railroad crossings. To overcome this problem, this study applied an ATMEGA8-based sensor device that can regulate traffic lights when the train is about to pass. When the train passes, the servomotor or the railroad cross will be closed. The buzzer will sound a long beep as a warning sound that a train is passing. The traffic light will be yellow for 3 seconds as a warning sign for road users. The LCD will display "be careful! The train will cross the road. The situation on the road is still normal". Then the infrared sensor starts working to detect the largest number of vehicles on Brigen Katamso street or on Letjen Suprapto Street.

If there is a long traffic jam on the road, the traffic light will be green and the other will be red. Furthermore, if the train has passed, the infrared sensor will return to normal and the railroad cross will be lifted, and the system is deactivated, and the situation returns to normal. The goal is to minimize the road congestion to prevent congestion on the road around the railroad crossings.

\section{CONCLUSION}

The results of this study indicate that the automatic traffic light system can work well and can detect traffic jams with photodiode sensors. The addition of an infrared photodiode sensor to the system can detect vehicles, and traffic congestion to match traffic lights on the road. The design of a traffic light system with infrared photodiode sensors and the information displayed on the display serves as a guide for vehicles on the road. All components that were assembled at every intersection and on the railroad run simultaneously so that the path of each component installed did not collide with each other.

This device functions as a sensor and cannot be used automatically to detect the density of vehicles at traffic lights. Therefore, further research can develop a CCTV camera detection system to detect the number of vehicles and can add Fuzzy Logic to traffic lights.

\section{REFERENCES}

EA Nugroho, "Traffic Light Control System Based on Fuzzy Logic,” J. SIMETRIS, vol. 8, no. 1, pp. 75-84, 2017.

D. Ramadhany, "Smart Traffic Light Simulation Using Artificial Neural Network," Thesis, 2020.

MD Sulistiyo, "Analysis and Implementation of Fuzzy Systems and Evolutionary Programming in Intelligent Traffic Light Settings," Conf. Nas. ICT-M Politek. Telkom, p. 8, 2017, [Online]. Available: http://journals.telkomuniversity.ac.id/knip/article/view/560.

B. Santoso, AIS Azis, and A. Bode, "Intelligent Traffic Light Control at a Complex Four-Road Intersection Using an Adaptive Neuro Fuzzy Inference System Algorithm," J. Education and Researcher. Inform., vol. 6, no. 1, p. 29, 2020, doi:10.26418/jp.v6i1.37311.

P. Software, I. Control, and L. Then, "Design software interface for controlling traffic lights at five intersections based on the microcontroller atmega8535," pp. 1-11.

I. Rahmawati, T. Hariyanto, and K. Kunci, "Automatic Traffic Light System Using Radio Network at $433 \mathrm{MHz}$ Frequency With Ultrasonic Sensor,” pp. 26-27, 2020.

I. Saputra and GM R, "The Prototype of Using Integrated Ultrasonic Sensors With Google Firebase Internet Network for Traffic Light Duration Management," pp. 26-27, 2020.

Ginting, AQ (2018). Making a Traffic Light Control System Using an Atmega 16 Microcontroller-Based LDR Sensor.

H. Himawan, "Prototype of Multi-Agent Based Adaptive Traffic Light Using Fuzzy Logic Embedded in Microcontroller," J. Teknol. Inf., vol. 12, pp. 84-102, 2016, [Online]. Available: http://research.pps.dinus.ac.id.

N. Rupawanti, "Automatic Smart Traffic Light Prototype Based on Atmega-328 with Proximity Sensor," E-Issn: 2686-0635, no. 0322, 2019.

SAPUTRA, Irvan, et al. Prototype of Using Ultrasonic Sensors Integrated With Google Firebase Internet Network For Traffic Light Duration Management. In: Proceedings of the Industrial Research Workshop and National Seminar. 2020. p. 287-292.

*name of corresponding author 
RAHMAWATI, Beautiful; HARIYANTO, Teddi. Automated Traffic Light System Using Radio Network at 433 MHz Frequency With Ultrasonic Sensor. In: Proceedings of the Industrial Research Workshop and National Seminar. 2020. p. 607-612.

KARTIKA, Linda; VIRGONO, Agus; SETIANINGSIH, Casi. Traffic Light System Analysis Using Artificial Intelligence. eProceedings of Engineering, 2018, 5.1.

WALUYO, APC (2018). Smart Traffic Light Model For Various Types Of Intersection And Time Flexibility Based On Arduino ATmega 328P. Thesis, 1(521410008).

Kaikai Liu. 2020. Deep Associated Elastic Tracker for Intelligent Traffic Intersections. In Proceedings of the 2nd International Workshop on Challenges in Artificial Intelligence and Machine Learning for Internet of Things (AIChallengeIoT '20).

Nishat Anjum Khan and Rashid Ansari. 2018. Real-time traffic light detection from videos with inertial sensor fusion. In Proceedings of the 1st ACM SIGSPATIAL Workshop on Advances on Resilient and Intelligent Cities (ARIC'18). Association for Computing Machinery, New York, NY, USA, 31-40.

Saif Islam Bouderba and Najem Moussa. 2019. Reinforcement Learning (Q-LEARNING) traffic light controller within intersection traffic system. In Proceedings of the 4th International Conference on Big Data and Internet of Things (BDIoT'19). Association for Computing Machinery, New York, NY, USA, Article 61, $1-6$. 